\title{
Ergonomic analysis of cleaning professionals: pilot study
}

\author{
Solange dos Santos ${ }^{1}$, J. Duarte ${ }^{2}$, A. D. Lucena ${ }^{3}$, J. C. Guedes ${ }^{4}$
}

${ }^{1}$ Faculty of Engineering, University of Porto, PT (solangel442@gmail.com) ORCID 0000-0002-2475-198X, ${ }^{2}$ Associated Laboratory for Energy, Transports, and Aeronautics (PROA/LAETA), Faculty of Engineering, University of Porto, PT (jasduarte@fe.up.pt) ORCID 0000-0002-5856-5317, ${ }^{3}$ Federal Rural University of Semiarid, BR (andrelucena@ufersa.edu.br) ORCID 000-0003-0181-4260, ${ }^{4}$ Associated Laboratory for Energy, Transports, and Aeronautics (PROA/LAETA), Faculty of Engineering, University of Porto, PT (jccg@fe.up.pt) ORCID 0000-0003-2367-2187 https://doi.org/10.24840/978-972-752-260-6_0123-0128

\begin{abstract}
Introduction: The cleaning activity is characterized by being an occupational activity performed mostly standing, adopting excessive bending of the lower back postures, high positioning of the arms, squatting, the repetitiveness of movements and use of non-ergonomic working tools that demand a high physical profile and agility of the worker. The physical, ergonomic, psychosocial and organizational factors are work-related risks for the emergence of musculoskeletal disorders. Being extremely demanding for the worker's musculoskeletal structure, the ergonomic analysis is fundamental. This pilot study aimed to assess the risk of musculoskeletal lesion of a professional cleaning worker due to the movements and task performance along the activity. Methodology: A cleaning professional was selected, observations in loco were made, and video/photos were collected, as well as anthropometric data and job-related information. The Nordic questionnaire was applied, and complemented by the REBA method. To determine the energy expenditure and prevent the appearance of injury it was performed an analysis with ActiGraph wGT3X-BT. In order to analyze the adopted postures, Microsoft Excel ${ }^{\circledR}$ and Actilife ${ }^{\circledR}$ software were used for data processing. Results and discussion: The results indicate that the worker has a high prevalence of painful symptomatology in the exposed regions due to the adopted postures, which may be indicative of musculoskeletal injuries. The study allowed to analyze the most affected body regions were the neck, hips/thighs, knees and ankles/feet. The ergonomic analysis revealed the working postures used during the activity constitute a high risk of musculoskeletal injury. Conclusions: The results are consistent with the existing literature and provide information that allows characterizing the working activity through the body segments: neck, shoulder, elbow, wrist / hand, chest area, lower back, hips / thighs, knees and ankles / feet according with the positions adopted by effectively working over the $8 \mathrm{~h}$ of work. With the results, it is possible to know the risks ergonomic that the worker is exposed, as well as improvements and/or changes in the form of execution of the activity.
\end{abstract}

Keywords: Ergonomic Analysis, Professional Cleaning, Actigraphy, Repetitive Movements, Posture Assessment.

\section{INTRODUCTION}

Professional cleaning is a physically demanding job that includes numerous and varied tasks, where workers are most of their time standing, lifting and/or pushing equipment. Thus, they undergo inadequate postures, repetitive movements and precarious situations (Dahlqvist, Nordander, Forsman, \& Enquist 2018). Such activities do not require any training instructions (Kumar \& Kumar, 2008). Several studies indicate that the cleaning tasks are characterized by static and repetitive muscle movements of the back, hands and legs, which leads to the necessity of using excessive strength or inadequate postures (Kalkis, Roja \& Kalkis, 2014). These workers have a high risk of developing health problems, particularly musculoskeletal problems, especially affecting the back, neck, shoulders, elbows and hands (Wang, Chen, \& Chiou, 2016). The risk of developing musculoskeletal injuries is multifactorial and is based on the level of physical activity of the workers not only within their occupational activity but also outside their work. This risk is developed through repetitive movements, inadequate postures, manual manipulation of loads, poor job conception (Wang et al., 2016). The actigraphy technique measured by the actigraphy wGT3X-BT allows the assessment of physical activity through parameters such as: energy expenditure, metabolic rate, activity level (sedentary, mild, moderate, vigorous, very vigorous), heart rate, magnitude vector description $(x, y, z)$, step-byminute counts, total sleep time, and to differentiate between sleep/awake periods through any body movement produced by skeletal muscles (Ribeiro, 2014). Therefore, it is possible to analyze movements and the execution of tasks (adopted postures) in the occupational activity 
through two traditional methods, Nordic Questionnaire (prevalence of musculoskeletal symptoms) (Kuorinka et al., 1987), and REBA (Rapid Body Assessment) method (Hignett \& McAtamney, 2000) and to validate these methods with the actigraphy technique and its parameters. So, this pilot study intended to analyze the positions adopted during the activity of a cleaning professional worker, assess the risk of musculoskeletal injury and determine the prevalence of musculoskeletal symptoms of the professional cleaning worker, to prevent the emergence of musculoskeletal injuries.

\section{MATERIALS AND METHODS}

The ergonomic analysis was carried out on-the-job, to a professional cleaning worker at Faculty of Engineering University of Porto (FEUP). This job has been chosen, because the tasks have long time cycles and, usually, the workers adopt incorrect postures. Without ignoring the cognitive and organizational domains, it is emphasized in the present study the physical domain as it has concern for anthropometric, physiological and biomechanical information of human beings in contact with their working environment. The study was developed by observing the target and simultaneously collecting anthropometric data, photo, videos and job-related information. The collected videos and photographs were subsequently analyzed in detail and the tasks were analyzed, and the postures that contribute to an increased risk of musculoskeletal injuries at work were identified. After the definition of tasks and target posture analysis, the worker was questioned about whether he had pain, aching or discomfort in the last twelve months and the last seven days in nine anatomical regions, which were, neck, shoulder, elbow, wrist/hands, chest area, lower back, hips/thighs, knees, ankles/feet. Where the working rated the prevalence of symptoms in anatomical regions on a scale of one to ten, according to the Portuguese version of the Nordic Questionnaire (Mesquita, Ribeiro, \& Moreira, 2010). The postures adopted by the working were analyzed according to REBA method (Rapid Body Assessment) (Kuorinka et al., 1987) applying six steps: observation of the task, postures assessed for EVALUATION, assign a score to the static postures, perform treatment of the score calculate the final score of the REBA and, lastly confirm the level of action and the urgency of the respective measures. The method uses a score sheet where they classified have classified body segments according to postures and activity levels of 1 to 15 , scoring is done by two groups $A$ and $B$ where A (trunk, neck, legs) and B ( arms, forearms, wrists) (Hignett \& Mc Atamney, 2000). It was used actigraphy (Actigraph WGT3x-BT) together with the heart rate monitor (Polar H7 Heart Rate), to evaluate the physical activity in temporal variations of the acceleration magnitudes of three individual planes $(x, y, z)$. These accelerations were converted through the Actilife software to calculate energy expenditure (EE), metabolic rate (MET) and the cutoff points activities (Barwais, Cuddihy, Rachele, \& Washington, 2013).

\section{RESULTS AND DISCUSSION}

The employee works 8 hours/day, work starts at 09: 00h and has a 10 min break from 10:00h to $10: 10 \mathrm{~h}$ and then have another break for lunch from 12: $00 \mathrm{~h}$ to $13: 00 \mathrm{~h}$ and leaves at $17: 00 \mathrm{~h}$. Figure 1 highlights some of the adopted postures by the professional cleaning worker during her activity: continuous dynamic muscle movement in the limbs under overload; repetitive or continuous movements, some under overload anteflexion and twisting of the spine; inadequate posture of the spine, knees and ankles; lack of working of awareness about the importance of minimizing occupational risk. 


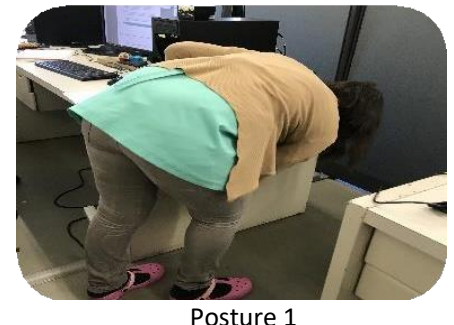

Posture 1

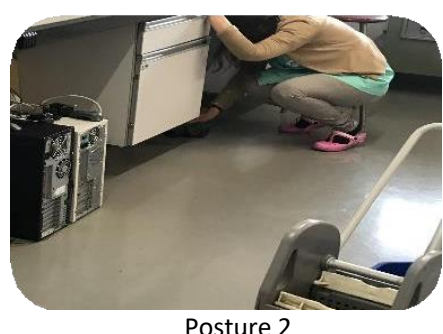

Posture 2

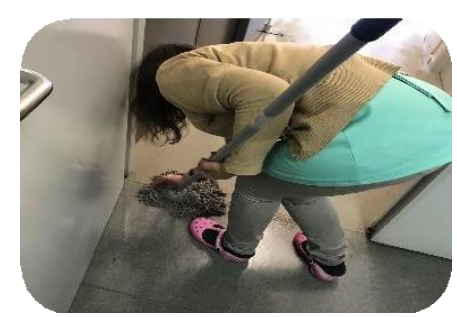

Posture 3

Figure 1. Adopted postures

The studied worker, while doing her activities, moved up for several hours with only two breaks (a $10 \mathrm{~min}$ for a snack in the morning and another one hour for lunch), mobilizing many myoarticular groups simultaneously or alternately in activities that required alternating postures, but all the time standing. In this case, although it is a dynamic activity, the standing posture determines a static load on the muscles that may contribute to the occurrence of pain in the lower limbs. This complaint was made by the worker through the Portuguese version of the Nordic questionnaire, indicating the prevalence of musculoskeletal injuries in one or more anatomical regions in a specific time interval, as shown in Figure 1. Pain intensity in different regions are represented as moderate pain, ranging between 4 and 5 on the neck and shoulders and regions with maximum intensity between 9 and 10 were lower back, hips/thighs and knees. These intensities prevail because the activity itself, and repetitive movements over the 25 years of work, requires working continuously with the anteflexion and torsion of the spine because of the handling of the broom, squeegee or can clean underneath the tables and under the cabinets. Professional cleaning is a dynamic job that requires a lot of muscle activity with repetitive movements and adoption of bad postures held for long, and for this reason the REBA analysis was done in two groups A (trunk, neck, legs) and B ( arms, forearms, wrists), the data obtained by REBA software (Employee Assessment Worksheet) proceeded to REBA analysis for tasks selected by the method verified the activity constitutes a high risk for emergence of musculoskeletal injury (SCl) with the exception of work done with the forearm in which it was classified as low. According to this tool and its authors (Mesquita et al., 2010) the level of activity for the total score 13 dictates that are necessary to implement changes (Hignett \& Mc Atamney, 2000).

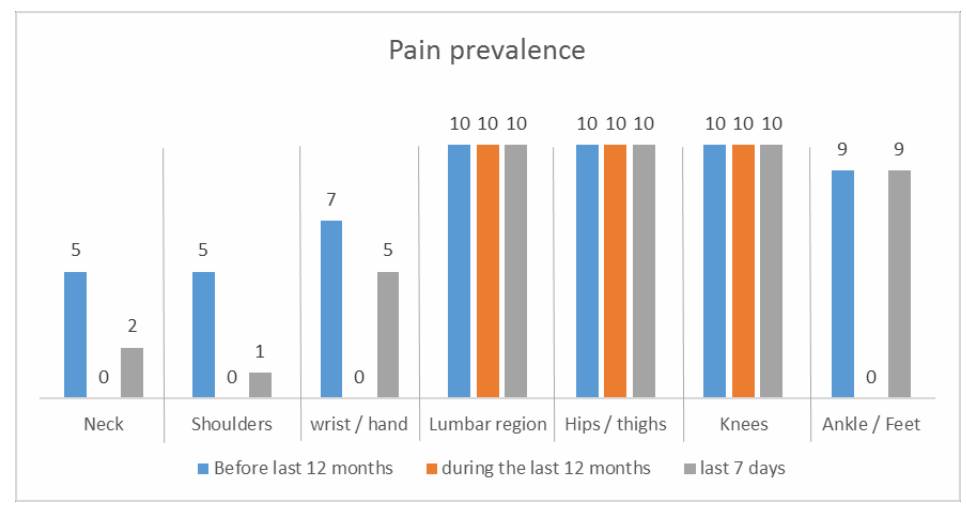

Figure 2. Pain prevalence

The magnitudes of the accelerations were calculated using the software Actilife for estimating energy expenditure by Equation Freedson VM3 combination (11). This software option combines Freedson VM3 equation (11) to the equation Williams Work-Energy (98). When the 
VMCPM is less than 2453 counts per minute software uses Formula (1), and when the VMCPM is greater than or equal to 2453 it uses Formula (2), where VMCPM vector is the magnitude of counts per minute, CPM is counts per minute, BM is body mass in $\mathrm{kg}$.

$$
\begin{aligned}
& \mathrm{VM} \text { is the sum of } \sqrt{\left((\text { Axis } 1)^{2}+(\text { Axis } 2)^{2}+(\text { Axis } 3)^{2}\right)} \\
& \frac{\text { Kcal }}{\min }=0,001064 \times V M+0,087512 \times(B M)-5,50022 \\
& \frac{\text { Kcal }}{\min }=C P M \times 0,0000191 \times(B M)
\end{aligned}
$$

Energy expenditure was calculated in the waist and wrist area where the most representative values were pulse with an average of $3.14 \mathrm{kcals} / \mathrm{min}$, where there is discrepancy in the amount of time an average of $10 \mathrm{~h}$ energy expenditure $3.85 \mathrm{kcals} / \mathrm{min}, 11 \mathrm{~h}$ averaging $4.00 \mathrm{kcals} / \mathrm{min}$, with an average of $13 \mathrm{~h} 3.33 \mathrm{kcals} / \mathrm{min}$ and $14 \mathrm{~h}$ with an average $4.21 \mathrm{kcals} / \mathrm{min}$. According to La Riva Rodríguez(2016), energy expenditure in industrial activities shall not exceed the limit of $4.2 \mathrm{kcal} / \mathrm{min}$ for men and $3.2 \mathrm{kcal} / \mathrm{min}$ for women. This discrepancy of values concerning the wrist due to dynamic use of arms to the activity itself, as to perform all working tasks whenever you use the wrist (hand). Regarding the energy expenditure (EE) in metabolic rate (MET) was calculated using the software used Actilife considering the equation (3) Swartz Adult overground and lifestyle, where CPM is counts per minute (Swartz et al., 2000). Moreover, the result is an average of the results obtained at the waist (MET 2.24) and wrist (MET 3.65).

$$
\text { MET Rate }=2,660+(0,0006863 \times C P M)
$$

In short, 1 MET is the amount of energy that the human body uses at rest. For example, a rate of 2.0 MET, indicates that during this period, the individual spends twice its energy sedentary standard(Ainsworth et al., 2011). There discrepancy value on the pulse zone in hours 9, 10, 11, $13,14,15$, the working spent four times its normal sedentary energy (BMR * 4). However, tasks which involve the movement of the upper body, such as ironing, washing and sweeping the sheets may require a gross energy expenditure $2-4 \mathrm{METs}(1 \mathrm{MET}=3.5 \mathrm{ml} \mathrm{O} 2 \cdot \mathrm{kg}-1 \cdot \mathrm{min}-1)$ (Hendelman, Miller, Baggett, Debold, \& Freedson, 2000). The hip accelerometer almost does not detect significant movement regarding the activity. Consequently, an accelerometer worn on the wrist may be able to explain the energy expenditure associated with the movement of the upper body involved in these types of tasks (Swartz et al., 2000). The metabolic rates (METs) are calculated using cut points for minutes (or ADCs) measured by the BT-ActiGraph wGT3X to rate the intensity of physical activity such as sedentary, mild, moderate and vigorous (Bai et al., 2016). To calculate the cutoff points the Actilife software used adult Freedson equation VM3 (2011) that utilize the values of the magnitudes of the accelerations per minute obtained by ActiGraph wGT3X-BT, and were classified as moderate activity movements in the axes $y$ and $z$ relative the wrist area. The values of the accelerations are more representative in the z-axis as the working always to fall and get up to perform their activities. The differences in counts per minute and metabolic rate (METs) similar activities are small and may be explained by external variability (BROOKS, GUNN, WITHERS, Gore, \& PLUMMER, 2005). Additional studies are needed 
to determine the validity of the regression equations and the cutoff points observed in both studies (Swartz et al., 2000).

\section{CONCLUSIONS}

This study focused on the ergonomic analysis of movements and tasks (as well as adopted postures) of a worker in the context of professional cleaning, where stood out as risk factors, repetitiveness of the movements, anteflexion and torsion of the spine and dynamic work of the lower limbs that affect the routine of the worker. These factors are related to the symptomatology of pain and discomfort manifested by the worker through the Portuguese version of the Nordic questionnaire and by the analysis of postures and repetitive movements through the REBA method. It was verified that the worker exercises her activity with discomfort, according to the prevalence of symptomatology applied by the Nordic questionnaire, and is at risk of developing musculoskeletal disorders, determined by the level of risk of the REBA method. This is due to the lack of knowledge on ergonomic principles from the worker, the workload and the activity itself. This study recommends an ergonomic intervention, complemented with the appropriate training of the worker regarding occupational health education on more appropriate postural changes, implementation and/or updating of the standards to recommend and reduce the risk of musculoskeletal disorders injury. This pilot study aims to contribute to a future study that will determine whether there is any relation or possibility to infer about the development of musculoskeletal injury from the technique of actigraphy through the parameters assessed such as: energy consumption, metabolic rate, activity level (sedentary, mild, moderate, vigorous, very vigorous), heart rate, among other parameters, as well as any skeletal muscles movement that are not recorded and assessed through the photographs and videos, in order to predict the risk of musculoskeletal injury and physical recovery during a period of continuous activity.

\section{References}

Ainsworth, B. E., Haskell, W. L., Herrmann, S. D., Meckes, N., Bassett Jr, D. R., Tudor-Locke, C.,... Leon, A. S. (2011). 2011 Compendium of Physical Activities: a second update of codes and MET values. Medicine \& Science in Sports \& Exercise, 43(, 1575-1581.

Bai, J., Di, C., Xiao, L., Evenson, K. R., LaCroix, A. Z., Crainiceanu, C. M., \& Buchner, D. M. (2016). An Activity Index for Raw Accelerometry Data and Its Comparison with Other Activity Metrics. PLOS ONE, 11(, 1-14. https://doi.org/10.1371/journal.pone.0160644

Barwais, F. A., Cuddihy, T. F., Rachele, J. N., \& Washington, T. L. (2013). ActiGraph GT3X determined variations in "free-living" standing, lying, and sitting duration among sedentary adults. Journal of Sport and Health Science, 2(4), 249-256. https://doi.org/https://doi.org/10.1016/j.jshs.2013.06.003

BROOKS, A. G., GUNN, S. M., WITHERS, R. T., Gore, C. J., \& PLUMMER, J. L. (2005). Predicting walking METs and energy expenditure from speed or accelerometry. Medicine \& Science in Sports \& Exercise, 37(7), 1216-1223.

Dahlqvist, C., Nordander, C., Forsman, M., \& Enquist, H. (201. Self-recordings of upper arm elevation during cleaning - Comparison between analyses using a simplified reference posture and a standard reference posture. BMC Musculoskeletal Disorders, 19(1). https://doi.org/10.1186/s12891-018-2328-8

de La Riva Rodríguez, J., Estrada, E. I., Reyes Martínez, R. M., \& Prieto, A. W. (2016). Determination of energy expenditure of direct workers in automotive harnesses industry. In C. Schlick \& S. Trzcieliński (Eds.), Advances in Intelligent Systems and Computing (Vol. 490, pp. 331-339). https://doi.org/10.1007/978-3-319-41697-7_29

Hendelman, D., Miller, K., Baggett, C., Debold, E., \& Freedson, P. (2000). Validity of accelerometry for the assessment of moderate intensity physical activity in the field. Medicine \& Science in Sports \& Exercise, 32(9), S442-S449. 
Hignett, S., \& Mc Atamney, L. (2000). REBA (Rapid Entire Body Assessment). Applied Ergonomi, 31, 201-205.

Kalkis, H., Roja, Z., \& Kalkis, V. (2014). Physical load analysis in hotel cleaning work. Agronomy Research, 12(3), 843-850. Retrievedfrom

https://www.scopus.com/inward/record.uri?eid=2-s2.084901473231\&partnerID=40\&md5=c770e9167b47fc889621a637ff92e1dd

Kumar, R., \& Kumar, S. (200. Musculoskeletal risk factors in cleaning occupation-A literature review. International Journal of Industrial Ergonomics, 38(2), 158-170. https://doi.org/10.1016/j.ergon.2006.04.004

Kuorinka, I., Jonsson, B., Kilbom, A., Vinterberg, H., Biering-Sørensen, F., Andersson, G., \& Jørgensen, K. (1987). Standardised Nordic questionnaires for the analysis of musculoskeletal symptoms. Applied Ergonomics, 18(3), 233237.

Löfqvist, L., Osvalder, A.-L., Bligård, L.-O., \& Pinzke, S. (2015). An analytical ergonomic risk evaluation of

Mesquita, C. C., Ribeiro, J. C., \& Moreira, P. (2010). Portuguese version of the standardized Nordic musculoskeletal questionnaire: cross cultural and reliability. Journal of Public Health, 18(5), 461-466.

Ribeiro, J. C. R. D. (2014). Estudo dos Determinantes da Atividade Física objetivamente Avaliada durante as aulas de Educação Física de $45 \mathrm{E} 90$ minutos.

Swartz, A. M., Strath, S. J., BASSETT, D. R., O’BRIEN, W. L., King, G. A., \& Ainsworth, B. E. (2000). Estimation of energy expenditure using CSA accelerometers at hip and wrist sites. Medicine \& Science in Sports \& Exercise, 32(9), S450S456.

Thach, Elizabeth C., Thompson, Karen J., Morris, A. (2006). A fresh look at followership: A model for matching Followership and leadership styles. Journal of Behavioral \& Applied Management, (1), 1-5. https://doi.org/10.1007/s13398-014-0173-7.2

Villumsen, M., Madeleine, P., Jørgensen, M. B., Holtermann, A., \& Samani, A. (2017). The variability of the trunk forward bending in standing activities during work vs. leisure time. Applied Ergonomics, 58, 273-280. https://doi.org/10.1016/j.apergo.2016.06.017

Wang, M.-H., Chen, B.-H., \& Chiou, W.-K. (2016). Redesign the cleaning tools from analysis of working postures at a cleaning job using the task analysis and OWAS methods. In Advances in Physical Ergonomics and Human Factors (pp. 417-426). Springer.

Welk, G. (2002). Physical activity assessments for health-related research. Human Kinetics. 